\title{
Isolation of regulatory mutants in photosynthesis gene expression in Rhodobacter sphaeroides 2.4.1 and partial complementation of a PrrB mutant by the HupT histidine-kinase
}

\author{
Mark Gomelsky and Samuel Kaplan
}

Department of

Microbiology and

Molecular Genetics, the

University of Texas Medical

School at Houston, Texas

77030, USA

\author{
Author for correspondence: Samuel Kaplan. Tel.: +1 713794 1744. Fax: +1 7137941782. \\ e-mail: skaplan@utmmg.med.uth.tmc.edu
}

Keywords: oxygen regulation, mutations, sensor kinase, cross-talk, hydrogen uptake

\section{INTRODUCTION}

The purple nonsulfur photosynthetic bacterium Rhodobacter sphaeroides demonstrates an incredible versatility in growth capability. In the presence of oxygen and a

Abbreviations: $\beta$-Gal, $\beta$-galactosidase; Hup, hydrogen uptake; $\mathrm{LH}$, light harvesting; PS, photosynthesis; $W T$, wild-type.

The GenBank accession numbers for the sequences reported in this paper are L37195 (hupT-hupU2' region), L37196 (hupS') and L37194 (hupL'). variety of carbon sources it grows as a typical Gramnegative bacterium using aerobic respiration. When the oxygen tension drops below certain threshold levels it develops an intracytoplasmic membrane which comprises the structural and functional components associated with photosynthesis (PS). Anaerobiosis is a prerequisite for this form of PS and even in the absence of light, the intracytoplasmic membrane with its assortment of photosynthetic spectral complexes is produced gratuitously. Anaerobic growth in the dark requires an exogenous 
oxidant (e.g. dimethyl sulfoxide) and is much slower than when light is available. In the latter case light energy is absorbed by the light-harvesting I and II (LH I and LH II respectively) complexes and the energy is ultimately transferred to the reaction centre which initiates conversion of this energy into chemical energy. LH I, LH II and the reaction centre complexes are composed of structural polypeptides with noncovalently bound photopigments: bacteriochlorophyll and bacteriopheophytin, and carotenoids (reviewed by Kiley \& Kaplan, 1988).

R. sphaeroides can also grow lithoautotrophically either aerobically or photosynthetically using $\mathrm{CO}_{2}$ as a sole source of carbon together with $\mathrm{H}_{2}$ as an electron source. $\mathrm{H}_{2}$ is most likely delivered to the cell by the hydrogen uptake (Hup) system as described for the related bacterium Rbodobacter capsulatus (Vignais \& Toussaint, 1994).

This study focuses on the mechanism of transcriptional control of the PS genes, in particular the puc operon, which encodes the structural polypeptides (Kiley \& Kaplan, 1987) and assembly factor(s) (Gibson et al., 1992; Lee et al., 1989b) for the LH II complex. Expression of most of the PS genes, including puc, depends on oxygen tension. puc-specific mRNA is barely detectable in aerobically grown cells yet it is highly abundant in cells growing photosynthetically (Kiley \& Kaplan, 1987). Eraso \& Kaplan (1994) described PrrA, a transcription regulator from $R$. sphaeroides 2.4.1 involved in the activation of anaerobic expression of the PS genes. This protein has a strong homology to the response regulators of other two-component regulatory systems (Stock $e t$ al., 1989). Mutations in the $\operatorname{prr} A$ gene of $R$. sphaeroides 2.4.1 result in a $\mathrm{PS}^{-}$phenotype and greatly reduced expression of a number of PS genes (Eraso \& Kaplan, 1994). The second gene, designated prrB (Eraso \& Kaplan, 1995), encodes a cognate histidine-kinase for PrrA. In $R$. capsulatus an analogous two-component ( $\operatorname{Reg} A$ and $R \operatorname{eg} B$ ) regulatory system has also been described (Inoue et al., 1995; Mosley et al., 1994; Sganga \& Bauer, 1992). PhillipsJones \& Hunter (1994) cloned and sequenced a prr A/ $\operatorname{reg} A$ homologue from yet another strain of $R$. sphaeroides and showed its ability to partially complement the R. capsulatus $\operatorname{reg} A$ mutation.

In order to facilitate a search for additional transcriptional regulators of puc operon expression we devised a simple technique allowing us to screen for changes in the strength of transcription of the puc operon in colonies of $R$. sphaeroides using puc: : lac $Z$ transcriptional fusions. Based on this technique, a collection of spontaneous mutants, unable to increase $p u c:: l a c Z$ expression after transition from aerobic to photosynthetic conditions, was obtained. In this paper we describe in detail one representative regulatory mutant complemented by either $\operatorname{prr} A$ or $\operatorname{prr} B$.

In addition, this approach led to the identification of other regulatory loci which, when present in extra copies, produce a strong effect on puc expression. One of these loci is characterized here and shown to be a bupT homologue of $R$. capsulatus, which has been proposed to encode a histidine kinase for the Hup system (Elsen et al., 1993). This observation, together with other ongoing studies, has helped us to assign the mutation giving rise to this original mutant to the $\operatorname{prr} B$ gene, which was confirmed by DNA sequencing. These studies also confirmed the proposed function of Hup T as a kinase and have given additional insight into functioning of the PrrB-PrrA two-component regulatory system.

In the course of this study we have cloned, sequenced and mapped some of the bup genes from $R$. sphaeroides and constructed a Hup ${ }^{-}$mutant. A preliminary report of this work has been presented (Gomelsky \& Kaplan, 1994a).

\section{METHODS}

Bacterial strains, phages and plasmids. These are listed in Table 1.

Growth conditions. Escherichia coli strains were grown at $37^{\circ} \mathrm{C}$ on LB medium (Maniatis et al., 1982) supplemented, where required, with the following antibiotics: tetracycline (Tc) $10 \mu \mathrm{g}$ $\mathrm{ml}^{-1}$, ampicillin (Ap) $100 \mu \mathrm{g} \mathrm{ml}^{-1}$, kanamycin (Km) $50 \mu \mathrm{g} \mathrm{ml}^{-1}$.

R. sphaeroides strains were grown aerobically at $30^{\circ} \mathrm{C}$ on Sistrom's medium A (Cohen-Bazire et al., 1957) containing succinate as carbon source. For anaerobic-dark growth $20 \%$ (v/v) LB and dimethyl sulfoxide (final concentration $80 \mu \mathrm{M}$ ) were added. Medium for photoautotrophic growth was devoid of succinate but supplemented with $0 \cdot 1 \% \mathrm{Na}_{2} \mathrm{CO}_{3}$ and $15 \mathrm{mM}$ $\mathrm{NiCl}_{2}$, and the concentration of $\left(\mathrm{NH}_{4}\right)_{2} \mathrm{SO}_{4}$ was raised to $7 \mathrm{mM}$ (Colbeau et al., 1980). Antibiotics were used, where appropriate, at the following concentrations: Tc $1 \mu \mathrm{g} \mathrm{ml} l^{-1}, \mathrm{Km} 50 \mu \mathrm{g} \mathrm{ml}^{-1}$, and streptomycin (Sm) + spectinomycin (Sp) at $50 \mu \mathrm{g} \mathrm{ml}^{-1}$ each.

\section{$\boldsymbol{\beta}$-Galactosidase ( $\beta$-Gal) assays}

(a) On colonies. Surfaces of Petri dishes containing up to $10^{4}$ colonies per plate to be tested were overlaid with approximately 6-9 $\mathrm{ml}$ soft agar $(0.7 \%)$ which contained $100 \mathrm{mM}$ phosphate buffer, $\mathrm{pH} 7.5$, and X-Gal. Concentrations of X-Gal $(0.1-0.3 \mathrm{mg}$ per $\mathrm{ml}$ soft agar) were varied according to the range of $\beta$-Gal levels expected, which in turn depended on the genetic background of the strains and conditions under which they had been grown. Plates were then left on a flat surface at room temperature and development of blue coloration was observed during 1-60 min. Supplementation of the growth medium with phenyl $\beta$-D-thiogalactoside $(80-200 \mu \mathrm{g}$ per $\mathrm{ml}$ medium), a competitive inhibitor of $\beta$-Gal, facilitated observation of colour differences in colonies expressing high levels of $\beta$-Gal. Since homogeneous blue coloration throughout a colony is unachievable, we relied on the blue coloration of the external 'crown' of the colony as an indicator of $\beta$-Gal activity. Natural pigmentation of $R$. sphaeroides interfered with, but did not preclude, utilization of this technique.

(b) In crude extracts. These assays were performed as previously described (Lee \& Kaplan, 1992a) at least twice with a standard deviation not exceeding $15 \%$ of the mean. Aerobic growth of liquid cultures was achieved by continuous bubbling with a mixture of $30 \% \mathrm{O}_{2}+69 \% \mathrm{~N}_{2}+1 \% \mathrm{CO}_{2}$ (by vol.), and the cells were collected at approximately the same cell density $\left(\mathrm{OD}_{600}\right.$ $0 \cdot 25-0 \cdot 30)$, which was low enough to avoid depletion of $\mathrm{O}_{2}$. For anaerobic-dark growth, screw-cap tubes were used.

Isolation of mutants unable to increase puc: lacZ expression following a shift to anaerobic photosynthetic conditions. To enrich the population of $R$. sphaeroides 2.4 .1 ( $\mathrm{pCF} 200 \mathrm{Km}$ ) for spontaneous PS mutants we grew cells for prolonged periods under conditions where the photosynthetic apparatus is produced gratuitously (Madigan $e$ t al., 1982), i.e. for $4 \mathrm{~d}$ semiaerobically or approximately $20 \mathrm{~d}$ anaerobically in the dark. 
Table 1. Strains, plasmids and phages used in this study

\begin{tabular}{|c|c|c|}
\hline $\begin{array}{l}\text { Strain, phage } \\
\text { or plasmid }\end{array}$ & Genotype or description & Reference \\
\hline \multicolumn{3}{|l|}{ Strains } \\
\hline \multicolumn{3}{|l|}{ E. coli } \\
\hline JM109 & $\begin{array}{l}\mathrm{F}^{\prime}, \operatorname{traD} 36 \text { lac } \Gamma^{\mathrm{q}} \Delta(\text { lac } Z) \mathrm{M} 15 \text { pro } A^{+} B^{+} / \mathrm{e}^{1} 4^{-} \Delta(\text { lac-pro } A B) \text { thi gyr } A \\
\text { end } A \text { bsdR } \operatorname{rel} A \sup E 44 \operatorname{rec} A\end{array}$ & Yanisch-Perron et al. (1985) \\
\hline DH5 $\alpha p b e$ & $\begin{array}{l}\mathrm{F}^{-} \phi 80 \Delta l a c Z \Delta \mathrm{M} 15 \Delta(\operatorname{lac} Z Y A-a r g F) \mathrm{U} 169 \operatorname{rec} A \text { end } A \text { bsdR supE44 thi } \\
\text { gyr } A \text { rel } A \text { phe:: } \operatorname{Tn} 10 d \mathrm{Cm}\end{array}$ & Eraso \& Kaplan (1994) \\
\hline S17-1 & $\mathrm{C} 600:: \mathrm{RP} 4-2(\mathrm{Tc}: \mathrm{Mu})(\mathrm{Km}:: \mathrm{Tn} 7)$ thi pro bsdR $\operatorname{rec} A$ & Simon et al. (1983) \\
\hline \multicolumn{3}{|c|}{ (6) } \\
\hline 2.4 .1 & Wild-type & W. R. Sistrom \\
\hline D5 & Spontaneous 2.4.1-derived PrrB mutant & \\
\hline $\mathrm{D} 5 \mathrm{H}$ & D5 HupSL ${ }^{-}\left(\right.$bup $S^{\prime}:: \Omega \mathrm{Km}^{\mathrm{r}}::^{\prime}$ bupL) $\mathrm{Km}^{\mathrm{r}}$ & This work \\
\hline PRRA1 & 2.4.1 $\operatorname{prr} A:: \Omega \mathrm{Sm}^{\mathrm{r}} / \mathrm{Sp}^{\mathrm{r}}$ & Eraso \& Kaplan (1994) \\
\hline \multicolumn{3}{|l|}{ Phages } \\
\hline $\mathrm{M} 13 \mathrm{mp} 18 / \mathrm{mp} 19$ & lac $Z \alpha$ (vectors for sequencing) & Yanisch-Perron et al. (1985) \\
\hline \multicolumn{3}{|l|}{ Plasmids } \\
\hline $\mathrm{pCF} 200 \mathrm{Km}$ & $\mathrm{Sm}^{\mathrm{r}} / \mathrm{Sp}^{\mathrm{r}} \mathrm{Km}^{\mathrm{r}}$ IncQ, contains transcriptional fusion $p u c:: \operatorname{lac} Z Y A^{\prime}$ & Lee \& Kaplan (1992b) \\
\hline pLA2917 & $\mathrm{Tc}^{\mathrm{r}} \mathrm{Km}^{\mathrm{r}}$ IncP cosmid vector & Allen \& Hanson (1985) \\
\hline pRK415 & $\mathrm{Tc}^{\mathrm{r}}$ lac $Z \alpha$ IncP & Keen et al. (1988) \\
\hline pRK4150 & pRK415 with inactivated lac $Z \alpha$ gene & This work \\
\hline pSUP202 & $\mathrm{Ap}^{\mathrm{r}} \mathrm{Cm}^{\mathrm{r}} \mathrm{Tc}^{\mathrm{r}} \mathrm{mob}$ & Simon et al. (1983) \\
\hline pUC19 & $\mathrm{Ap}^{\mathrm{r}} \operatorname{lac} \mathrm{Z} \alpha$ & Yanisch-Perron et al. (1985) \\
\hline PUI1621 & pRK415 containing the prr $A$ gene & Fraso \& Kanlan (1994) \\
\hline pUI1637 & $\mathrm{Ap}^{\mathrm{r}} \mathrm{Km}^{\mathrm{r}}$ (source of $\Omega \mathrm{Km}^{\mathrm{r}}$ cartridge) & Eraso \& Kaplan (1994) \\
\hline pUI8043 & pLA2917-derived cosmid containing bup genes & \\
\hline pUI8382 & pLA2917-derived cosmid containing $p r r A$ and $p r r B$ genes & Dryden \& Kaplan (1990) \\
\hline pUI8533 & pLA2917-derived cosmid containing $p r r A$ and $p r r B$ genes & \\
\hline $\mathrm{p} 43-\mathrm{Hp}$ & pUI8043/HpaI, ligated (deletion of the HpaI fragment of pUI8043) & \\
\hline $\mathrm{p} 43-\mathrm{B}$ & $\begin{array}{l}\text { pUI8043/BamHI, ligated (deletion of the internal BamHI fragments } \\
\text { of the insert of pUI8043) }\end{array}$ & \\
\hline $\mathrm{p} 43-\mathrm{H}$ & $\begin{array}{l}\text { pUI8043/HindIII, ligated (deletion of the HindIII fragments of } \\
\text { pUI8043) }\end{array}$ & \\
\hline $\mathrm{p} 43-\mathrm{BH}$ & p43-B/HindIII, ligated (deletion of the HindIII fragment of p43-B) & \\
\hline p43-BS2 & pRK415/SacI + approx. $3 \cdot 1 \mathrm{~kb}$ SacI fragment of p43-BH & \\
\hline $\mathrm{p} 43-\mathrm{BS} 2 \mathrm{~K}$ & p43-BS2/KpnI, ligated (deletion of the $K p n I$ fragment of p43-BS2) & \\
\hline $\mathrm{p} 43-\mathrm{KS} 27$ & $\begin{array}{l}\mathrm{pRK} 415 / K p n \mathrm{I}-S_{a c} \mathrm{I}+\text { approx. } 2.7 \mathrm{~kb} K p n \mathrm{I}-S_{a c \mathrm{I}} \text { fragment from } \mathrm{p} 43- \\
\mathrm{BH} / K p n \mathrm{I}-S_{a c} \mathrm{I} \text { (partial digest) }\end{array}$ & \\
\hline p43-KS19 & $\begin{array}{l}\mathrm{pRK} 415 / K p n \mathrm{I}-S_{a c \mathrm{I}}+\text { approx. } 1.9 \mathrm{~kb} K p n \mathrm{I}-S_{a c \mathrm{I}} \text { fragment from } \mathrm{p} 43- \\
\mathrm{BH} / K p n \mathrm{I}-S_{a c} \mathrm{I} \text { (partial digest) }\end{array}$ & This work \\
\hline p43PH5 & $\begin{array}{l}\text { pUC19/PstI-HindIII + approx. } 5 \mathrm{~kb} \text { PstI-HindIII fragment from } \\
\text { p43-H }\end{array}$ & \\
\hline p43PHp & $\begin{array}{l}\mathrm{p} 43 \mathrm{PH} 5 / H p a \mathrm{I}-H i n d I I I, \text { PolIk*, ligated (deletion of the HpaI- } \\
\text { HindIII fragment of } \mathrm{p} 43 \mathrm{PH} 5 \text { ) }\end{array}$ & \\
\hline $\mathrm{p} 43 \mathrm{PHp}:: \mathrm{Km}$ & 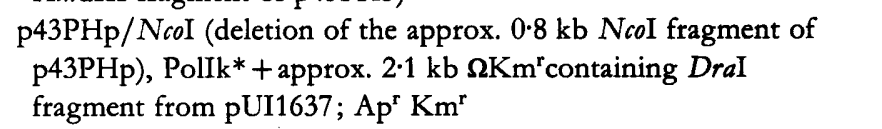 & \\
\hline p43PHp::Km::mob & 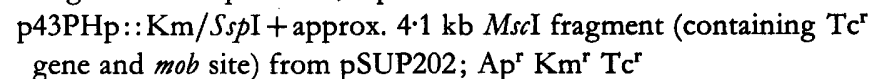 & \\
\hline
\end{tabular}

* Pollk, Klenow fragment of DNA polymerase I+dNTP.

These cultures were then plated (approx. $10^{3}-10^{4}$ cells per plate) and grown aerobically. When colonies were observed, the plates were taped to cardboard stands and placed into type A multiplate Bio-Bags (Becton Dickinson Microbiology Systems) under anaerobic conditions and exposed to $10 \mathrm{~W} \mathrm{~m}^{-2}$ illumination for
8-10 h. These conditions are sufficient for wild-type (WT) cells to undergo the transition to photosynthetic growth and correspondingly to increase expression of the chromosomal puc operon as well as the puc: : lacZ fusion provided on pCF $200 \mathrm{Km}$. By overlaying these plates with X-Gal, we were able to readily 
discriminate colonies (or sectors of colonies) of potential mutants, which became blue at either a faster or slower rate than the parental WT population. These mutants demonstrated abnormal $p u c:$ : lac $Z$ expression and hence carried potential PS regulatory mutations. The frequency of appearence of such mutant clones was approximately $10^{-3}-10^{-4}$ after enrichment.

After streak-purification all potential mutants were cured of pCF $200 \mathrm{Km}$ by several passages through antibiotic-free medium and the original $\mathrm{pCF} 200 \mathrm{Km}$ was reintroduced into each by conjugation. Only trans mutants, i.e. those having mutations residing on the chromosome, were further analysed.

Conjugation techniques. These were essentially as described by Davis et al. (1988). E. coli S17-1 was used as a donor transferring either IncQ or IncP plasmids to R. sphaeroides strains.

Spectrophotometric assay of $\boldsymbol{R}$. sphaeroides cell-free extracts. This was performed as described previously (Lee \& Kaplan, 1992a), using samples containing $0.7 \mathrm{mg}$ protein $\mathrm{ml}^{-1}$.

DNA manipulations and sequence analysis. Standard recombinant DNA techniques (Maniatis et al., 1982) and molecular biological enzymes and reagents were used according to the specifications of the manufacturers. Pulsed-field gel electrophoretic analysis of the R. sphaeroides genome has been described (Suwanto \& Kaplan, 1989). Sequencing was performed on an ABI 373A automatic DNA sequencer (Applied Biosystems) at the DNA Core Facility of the Department of Microbiology and Molecular Genetics, University of Texas. Templates for sequencing were either M13 mp18/mp19- or pUC19-based subclones of the DNA regions of interest. For sequence analysis the GCG software package of the University of Wisconsin and GenBank/EMBL and SwissProt databases were used.

\section{RESULTS}

\section{Rationale for isolation and classification of regulatory mutants in PS gene expression}

Grown aerobically on solid medium, $R$. sphaeroides forms colonies that are red-pigmented in the centre (due to the presence of photopigments) and colourless at the periphery. The level of photopigments ultimately depends upon the oxygen tension (Cohen-Bazire et al., 1957). Cells at the periphery of a colony are exposed to the oxygen from air, whereas cells in the centre of a colony are oxygen limited. Because most of the PS genes in R. sphaeroides as well as in $R$. capsulatus are regulated by oxygen tension (Bauer et al., 1993, and references therein; Eraso \& Kaplan, 1994; Kiley \& Kaplan, 1988, and references therein; Lang et al., 1994; Lee et al., 1989a, b; Lee \&
Kaplan, 1992a, b; McGlynn \& Hunter, 1993), to some extent the pattern of their expression is reflected in the changes associated with colony pigmentation. As a result, regulatory mutants in PS gene expression have been isolated relying on pigmentation as an indicator of the level of PS gene expression (Pollich et al., 1993; Sganga \& Bauer, 1992).

However, numerous factors, which are not involved in the transcriptional control of PS gene expression, contribute to colony pigmentation. Because we were interested in the identification of transcriptional regulatory factors, we sought to develop a more direct visual indicator of the level of PS gene(s) transcription. Therefore, we turned our attention to the exploitation of lac $Z$ transcriptional fusions. We adapted the $\mathrm{X}-\mathrm{Gal}$-based assay of estimating $\beta$-Gal activity to directly monitor lac $Z$ expression levels in colonies of $R$. sphaeroides.

Using a lac $Z$ transcriptional fusion to the $p u c$ operon (Lee \& Kaplan, 1992a), we were able to obtain a collection of puc regulatory mutations which displayed either increased or decreased puc: : lac $Z$ expression following exposure to anaerobic photosynthetic conditions. Mutants displaying decreased puc expression were further classified based on the pigmentation of colonies grown on solid medium, photosynthetic growth, spectral characteristics and complementation patterns. Roughly, they fall into three broad classes (see Table 2 and Fig. 1).

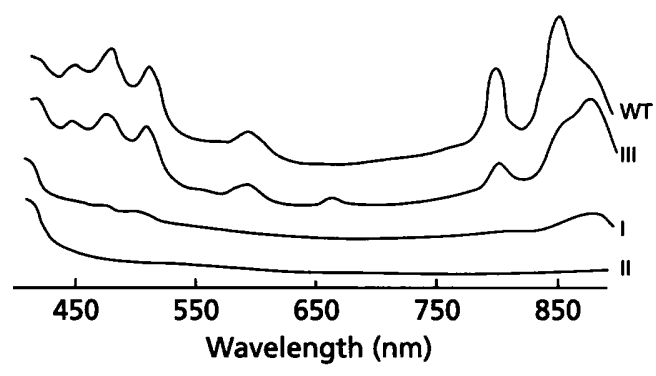

Fig. 1. Absorption spectra of representatives from mutant classes: I, mutant D5; II, mutant DD11; III, mutant DD26; and 2.4.1, WT. All cells were grown photosynthetically $\left(10 \mathrm{~W} \mathrm{~m}^{-2}\right)$ except for the mutant DD11, which was grown under anaerobic-dark conditions because of its inability to grow photosynthetically.

Table 2. Phenotype and complementation pattern of presumptive regulatory mutants of $R$. sphaeroides unable to increase puc::lacz expression in response to aerobic-anaerobiclight transitions

\begin{tabular}{|llccc|}
\hline $\begin{array}{l}\text { Mutant } \\
\text { class }\end{array}$ & Pigmentation & $\begin{array}{c}\text { Photosynthetic } \\
\text { growth }\end{array}$ & \multicolumn{2}{c|}{ Complementation } \\
\cline { 3 - 5 } & & & pUI8533/full & pUI8043/partial \\
\hline I & Pink & $\mp$ & + & + \\
II & Colourless & - & + & - \\
III & Approx. WT & + & - & NA \\
\hline
\end{tabular}

NA, Not applicable. 


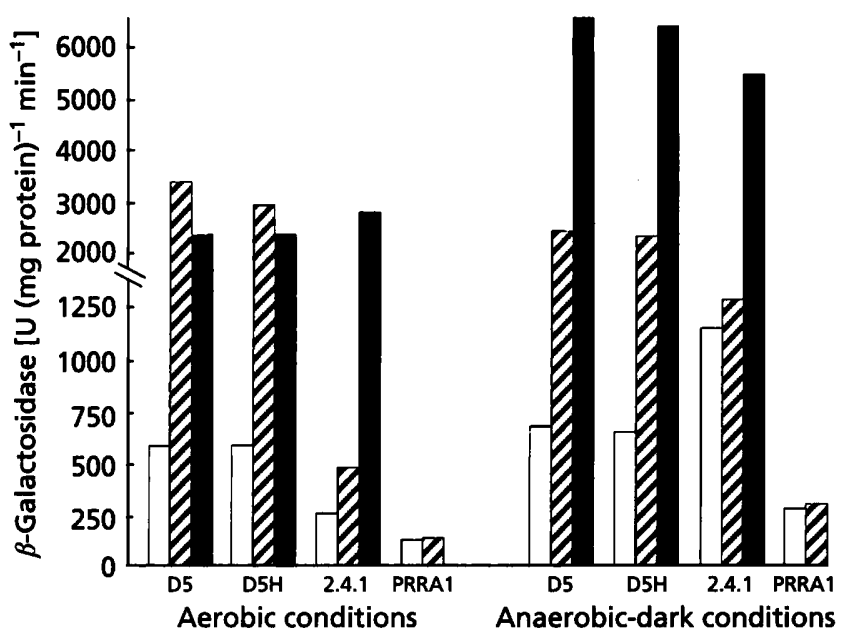

Fig. 2. Expression of puc::lacZ from plasmid pCF200Km in $\boldsymbol{R}$. sphaeroides strains, carrying a second plasmid: white bars, vector pLA2917 (pRK4150 instead of pLA2917 in strain PRRA1); hatched bars, p43-KS19; black bars, pUl8533.

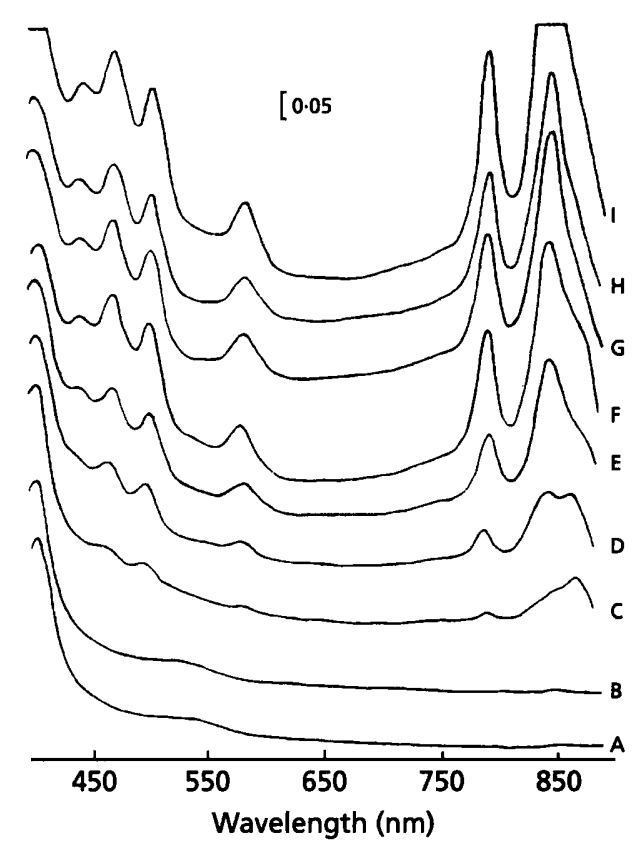

Fig. 3. Absorption spectra of anaerobic-dark grown cells: A, PRRA1(pRK4150); B, PRRA1(p43-KS19); C, D5(pLA2917); D, D5(p43-KS19); E, D5(pUl1621); F, D5(pUI8533); G, 2.4.1(pLA2917); H, 2.4.1(p43-KS19); I, 2.4.1(pUl8533). The bar represents an absorbance value of 0.05 .

Mutants of class I were characterized by their ability to form only low levels of photosynthetic complexes (Fig. 1, trace I) and therefore were capable of slow photosynthetic growth under high $\left(100 \mathrm{~W} \mathrm{~m}^{-2}\right)$ and medium $\left(10 \mathrm{~W} \mathrm{~m}^{-2}\right)$ but not low $\left(3 \mathrm{~W} \mathrm{~m}^{-2}\right)$ light intensities. When grown on solid medium under aerobic conditions, class I mutants formed light to intense pink colonies, in contrast to the more red-coloured WT colonies. These mutants were subsequently found to be complemented by cosmids pUI8533 and pUI8382 of the R. sphaeroides cosmid library and partially complemented by a number of other cosmids, including pUI8043 (see below). Mutants of class II were unable to form photosynthetic complexes (Fig. 1, trace II) and therefore were photosynthetically incompetent; they formed colourless colonies on solid medium and were also complemented by pUI8533 and pUI8382 and not affected by pUI8043 (see below). The phenotype of class II mutants resembled that of the $\operatorname{prr} A$ knock-out strain, PRRA1, constructed by Eraso \& Kaplan (1994). Mutants of class III were capable of accumulating significant, but less than WT amounts of photosynthetic complexes. Some mutants of this class accumulated lower levels of both LH I and LH II complexes (not shown), while others were more impaired in the accumulation of LH II complexes relative to LH I (Fig. 1, trace III). Under photosynthetic conditions, these mutants grew more slowly than WT. Their pigmentation on solid medium differed slightly from that of WT. In general, mutants of class III displayed more diverse phenotypes than the mutants of classes I and II; therefore it is possible that they contain mutations in different loci and are themselves of heterogeneous origin.

In this study we have focused on class I mutants and mutant D5 as a representative of this mutant class.

\section{Characterization and complementation of mutant D5}

As described in Methods, all mutants isolated, including class I mutants, were unable to increase to WT levels the expression of a puc: : lac $Z$ transcriptional fusion residing in trans on $\mathrm{pCF} 200 \mathrm{Km}$ in response to a shift from aerobic to anaerobic-light (photosynthetic) growth conditions. In order to determine whether class I mutants were impaired in either the oxygen or light regulation of puc::lac $Z$ expression, we examined levels of $\beta$-Gal under anaerobicdark growth conditions. Under these conditions, mutants of class I demonstrated decreased puc: : lac $Z$ expression when compared to the WT strain. As shown in Fig. 2, the level of $\beta$-Gal in mutant D5, containing in trans pCF $200 \mathrm{Km}$ as well as the second control plasmid, pLA2917, was approximately $1 \cdot 8$-fold lower than the level of $\beta$-Gal in WT containing the same two plasmids in trans, 2.4.1(pCF200Km, pLA2917). However, aerobic expression from puc::lacZ in D5(pCF200Km, pLA2917) was higher when compared to 2.4.1(pCF200Km, pLA2917) (Fig. 2). Taken together, these observations indicated that the defect of mutant D5 and of other class I mutants was associated with the oxygen/anaerobic regulation of puc operon transcription. Decreased abundance of the coloured carotenoids (absorbance at 450-550 nm) and LH I complex (absorbance maximum at $875 \mathrm{~nm}$ ) (Fig. 1, trace I) in mutant D5 in comparison to WT (Fig. 1, trace WT) suggested that the mutation(s) not only affected puc operon expression, but expression of other PS genes as well.

To determine the origin of the mutation(s), the $R$. sphaeroides 2.4.1 cosmid bank was crossed into two mutants of class I, including D5. The exconjugants were 


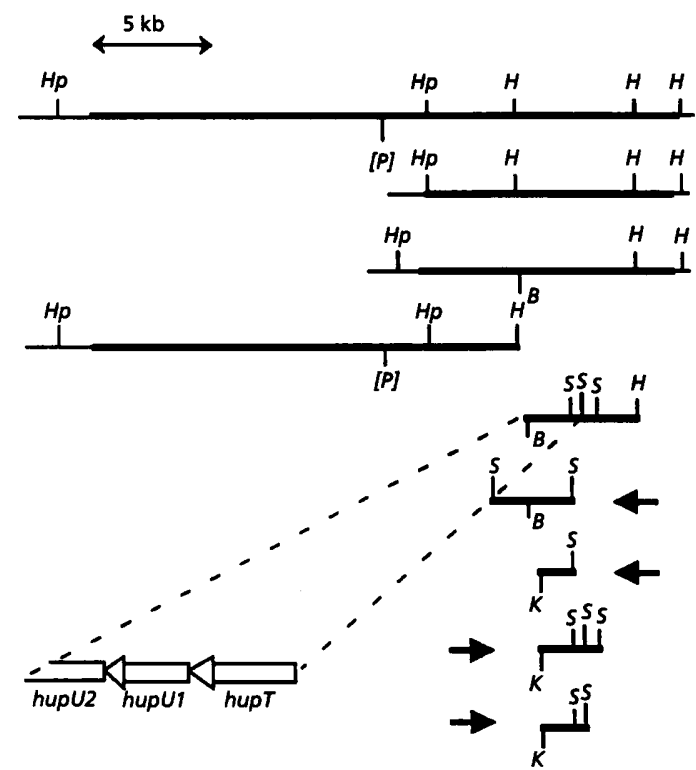

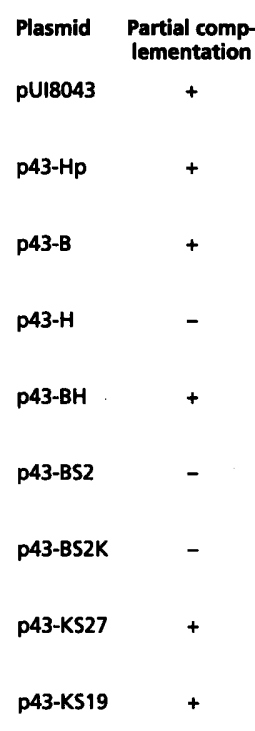

Fig. 4. Subcloning of the $1.9 \mathrm{~kb}$ Kpnl-Sacl fragment from cosmid pUl8043, responsible for the partial complementation of the class I mutants. Thick lines correspond to the $R$. sphaeroides DNA, thin lines correspond to vector DNA. Abbreviations: $B, B a m H I ; H$, HindIII; Hp, Hpal; K, Kpnl; [P], Pstl site used for localization of hupSL genes; S, Sacl. Only restriction sites relevant to subcloning are shown. Solid arrows indicate direction of tet and lac promoters of the vector pRK415. examined for photosynthetic growth at low light intensity, restoration of colony pigmentation and puc:: lac $Z$ expression. Two cosmids, pUI8533 and pUI8382, showed restoration of all of these parameters to levels resembling those of WT. As shown in Fig. 2, aerobic and anaerobicdark expression of puc: : lacZ in D5(pCF200Km, pUI8533) and 2.4.1 (pCF200Km, pUI8533) were similar. In addition, pUI8533 restored photopigment complexes in anaerobicdark grown D5(pUI8533) (Fig. 3, trace F) to the level observed in WT, 2.4.1(pLA2917) (Fig. 3, trace G), but less than the level observed in 2.4.1(pUI8533) (Fig. 3, trace I).

Cosmid pUI8533 contains the photosynthetic response regulator gene $\operatorname{prr} A$ (Eraso \& Kaplan, 1994). Comparison of the restriction maps of pUI8533 and pUI8382 followed by functional analysis revealed that the two cosmids share an approximately $10 \mathrm{~kb}$ DNA fragment which includes the $\operatorname{prr} A$ gene (data not shown). When various subclones derived from pUI8533 were used in trans in D5, it was found that either plasmid pUI1621, containing the $\operatorname{prr} A$ gene alone (Eraso \& Kaplan, 1994), or a plasmid containing only the $p r r B$ gene, encoding a histidine-kinase for PrrA (Eraso \& Kaplan, 1995) complemented mutant D5.

Because the $\operatorname{prr} A$ gene product acts downstream from $\operatorname{PrrB}$, we reasoned that the mutation in D5 was likely to reside in the $\operatorname{prr} B$ gene. This was ultimately proven to be correct when an insertion of a $G$ into a sequence of six $G s$ (GenBank accession no. U22347) in prrB was shown to have occurred in mutant D5 (J. M. Eraso \& S. Kaplan, unpublished), resulting in a shift in the ORF after amino acid 103 of PrrB.

However, there remained the observation that mutant D5, as well as other mutants of class I, could be partially complemented by a number of cosmids known to contain neither the $\operatorname{prr} A$ nor $\operatorname{pr} B$ genes. When present in trans in class I mutants, these cosmids displayed multiple effects, i.e. partial restoration of pigmentation and substantially increased puc: : lac $Z$ expression, and some of the cosmids also displayed an improvement in photosynthetic growth. Partial restoration of some or all of these properties in the mutants will be referred to as partial complementation. We neither anticipated partial complementation by the number of cosmids observed nor its potential implications for PS gene expression. To both investigate this phenomenon and assess the relationship(s) between the cosmids and the PrrB-PrrA signal transduction pathway, we characterized, in detail, one of these cosmids, pUI8043.

\section{Analysis of cosmid pUI8043}

pUI8043 was one of a group of nine cosmids which demonstrated a considerable complementation effect on class I mutants, but not on mutants of the other classes. To investigate the nature of the interaction between a gene(s) encoded by pUI8043 and the PrrB-PrrA regulatory system, this cosmid was chosen for further analysis. Fig. 4 summarizes the subcloning of pUI8043 which resulted in the localization of a $1.9 \mathrm{~kb} K p n \mathrm{I}-S_{a c \mathrm{I}}$ fragment responsible for the partial complementation. Fig. 3 (trace D) shows the spectrum of D5 containing in trans the $1.9 \mathrm{~kb} \mathrm{KpnI-SacI}$ fragment from pUI8043 on the plasmid p43-KS19. An increase in the abundance of spectral complexes (e.g. 2·8-fold for the LH II complex) is evident in D5 due to the presence of p43-KS19 when compared to D5(pLA2917) (Fig. 3, trace C). However, the effect of p43-KS19 in trans was substantially less than that of pUI8533 containing the $\operatorname{prr} A$ and $\operatorname{prr} B$ genes (Fig. 3, trace F) or pUI1621 containing the $\operatorname{prr} A$ gene alone (Fig. 3, trace $\mathrm{E})$, hence the designation partial complementation.

The most likely reason for the increased abundance of spectral complexes in response to the presence of $\mathrm{p} 43$ KS19 was increased transcriptional activity of the PS genes. This assumption was supported by the pattern of puc: : lac $Z$ expression in $\mathrm{D} 5(\mathrm{pCF} 200 \mathrm{Km})$ cells harbouring 
either pLA2917 or p43-KS19 in trans. Under anaerobicdark growth conditions, $\beta$-Gal activity in $\mathrm{D} 5(\mathrm{pCF} 200 \mathrm{Km}$, p43-KS19) was approximately 3.7-fold higher than in D5(pCF200Km, pLA2917) (Fig. 2). Under aerobic conditions, the difference in $p u c:$ lac $Z$ expression between these two strains was even greater, approximately $5 \cdot 6$-fold (Fig. 2). Therefore, the effect of p43-KS19 on puc::lac Z expression in mutant D5 appeared to be independent of the presence of oxygen. In the WT genetic background, the presence of $\mathrm{p} 43-\mathrm{KS} 19$ in trans resulted in virtually no increase in puc::lac $Z$ expression under anaerobic-dark conditions, and an approximately 1.7 -fold increase under aerobic conditions (Fig. 2). Thus, the effect of p43-KS19 was much more pronounced in D5 cells than in the WT strain.

\section{Sequence analysis and identification of the hupT gene}

The $1.9 \mathrm{~kb} \mathrm{KpnI-SacI} \mathrm{fragment} \mathrm{as} \mathrm{well} \mathrm{as} \mathrm{the} \mathrm{adjacent}$ DNA regions have been sequenced. Analysis of the DNA sequence (Fig. 5a) revealed three potential ORFs with codon usage characteristic of $R$. sphaeroides. All the ORFs are encoded by the same DNA strand and appear to be part of an operon, since the start codon of each downstream ORF overlaps with the stop codon of the preceding ORF. Potential Shine-Dalgarno (SD) sequences are positioned at the appropriate distances from the start codons of all the ORFs (Fig. 5a).

Only ORF1 (179-1510) is intact on p43-KS19. A truncated form (approx. $41 \%$ of the entire length) of ORF2 (1507-2499) is also present on p43-KS19, but its contribution to the partial complementation of mutant D5 could be excluded. In other constructions, either a truncated (in p43-BS2K) or a full-length (in p43-BS), ORF2 failed to partially complement D5 (Fig. 4).

Database searches revealed significant homology of ORF1 to a number of sensor kinases (data not shown) corresponding to two-component regulatory systems (Stock et al., 1989) and particularly to the HupT (also known as HupR2) protein from R. capsulatus (HupT-Rc) (Elsen $e t$ $a l ., 1993)$. HupT-R $c$ has been proposed to be a histidinekinase involved in the regulation of bup gene expression (Elsen et al., 1993). All previously identified domains characteristic of histidine-kinases are conserved in HupT$R c$ and ORF1. Overall similarity between these two proteins (which are $61 \%$ identical) (Fig. $5 \mathrm{~b}$ ) indicated that ORF1 is a homologue of HupT-Rc, i.e. HupT-Rs.

Sequence similarity between $R$. sphaeroides and $R$. capsulatus DNA continued downstream from the bupT gene. ORF2 (designated HupU1-Rs) was found to correspond to the N-terminus of the $R$. capsulatus HupU protein (approx. $71 \%$ amino acid identity) (Fig. 5c). HupU-Rc is encoded by the gene immediately downstream of $b u p T-R c$; the start codon of bupU-Rc overlaps the stop codon of bupT-Rc (Elsen et al., 1993). The analogous overlap between the bupT-Rs stop codon and the bupU1-Rs start codon was also observed in $R$. sphaeroides. ORF3 (designated HupU2-Rs) appears to be homologous (approx. $81 \%$ amino acid identity) to the Cterminus of HupU-Rc (Elsen et al., 1993). Thus, bupU-Rc may be considered as an in-frame fusion of bupU1-Rs and bupU2-Rs. It is worth mentioning that the bupU-Rc gene by itself is remarkably similar to the structural genes of the hydrogenase, bupS-Rc and bupL-Rc, correspondingly in its 5'- and 3'-domains (Elsen et al., 1993; Leclerc et al., 1988). The border between the bupU1-Rs and bupU2-Rs genes lies at the site where homology of the first with bupS-Rc stops and homology of the second to bupL-Rc begins. Thus the bupU genes are most likely the result of gene duplication of the bupSL-Rs region or recombination with heterologous bup genes (Elsen et al., 1993).

\section{Effect of HupT-Rs on PS gene expression appears to be independent of a functioning Hup system}

It is possible that the effect of bupT on PS gene expression is mediated through the presence of a functional Hup system, which is considered to be the primary target for regulation by HupT (Elsen et al., 1993). To examine this possibility, we constructed a $\mathrm{Hup}^{-}$mutant devoid of the structural genes encoding the Hup hydrogenase.

In $R$. capsulatus, the Hup hydrogenase consists of three subunits, HupS, HupL and HupC (HupM), which physiologically function as a $\mathrm{H}_{2}$ uptake enzyme (Vignais \& Toussaint, 1994). HupT-Rc dramatically affects the expression of the bupSLC-Rc operon encoding the Hup hydrogenase (Elsen et al., 1993). Unfortunately the Hup system in $R$. sphaeroides has not been extensively studied, in contrast to that in $R$. capsulatus. However, because of the high degree of sequence similarity between the DNA regions encoding the bup genes in these two bacteria we relied on the studies in $R$. capsulatus in planning our experiments and interpreting the results.

In accordance with the organization of the bup genes in $R$. capsulatus (Colbeau et al., 1993), we anticipated that the start of the structural gene operon for Hup hydrogenase, i.e. bupSLC-Rs, would be positioned approximately $5 \mathrm{~kb}$ downstream from the bupT-Rs stop codon, i.e. downstream of the internal $\mathrm{HpaI}$ site (Fig. 4) of pUI8043. The HindIII-PstI fragment containing this $\mathrm{HpaI}$ site was cloned into pUC19 to give p43PH5 (Fig. 6). As anticipated, DNA sequence downstream from the $\mathrm{HpaI}$ site (Fig. 7a) was found to be homologous to the coding region of bupS-Rc (Leclerc et al., 1988) (approx. $91 \%$ amino acid identity) (Fig. 7b) and included the 5'noncoding sequence. The left end of the insert in p43PH5 contained the $5^{\prime}$-end of the bupL-Rs gene (Fig. 7a), whose gene product was approximately $89 \%$ identical to the $\mathrm{N}$ terminus of HupL-Rc (Leclerc et al., 1988) (Fig. 7b). The striking degree of amino acid sequence homology confirmed our initial assumption that the insert in p43PHp contains the structural genes for the Hup hydrogenase.

We made a construction in which the $0.8 \mathrm{~kb} \mathrm{NcoI}{ }^{(1)}$ $\mathrm{NcoI}^{(2)}$ fragment, containing most of the bupS-Rs sequence and extending to the start codon of $b u p L-R s$, was replaced by an $\Omega \mathrm{Km}^{\mathrm{r}}$ cartridge (Fig. 6). A suicide plasmid p43PHp::Km::mob, containing the construction 
(a) GAG CTC GTG TCA CGG CAT GAT CGG CCC GGA AAC COG CGC GCG CCG CAT CCT CGT CIC CGT CIG TIC GCG ACC TGC CAG CCG GCG GGG CCC CGG CTG CCT CGA CCC CCG GAG AGG ACG CCG 121

AGC GCC CGG CCT TTC CAC CCC GAG GCC AAC AGG TCT ATG ATC GGC GCG GGA GGC ACC CAT

181 ORI1 Met

GGC GAA ACC GCA GSC ACC GCG CGA GGG AGA CGG CGA TCC GGT CTG GGC CGA CTC GGT CTG ala lys pro gln ala pro arg glu gly asp gly asp pro val trp ala asp ser val trp 241

GAT GGA CGT CAT GTC GGC CGT CGA CCG GAC CTA TGC CGA TCT CGT GGA CTA TCA GGA GCG met asp val met ser ala val asp arg thr tyr ala asp leu val asp tyr gln glu arg 301

GCT CGA GCG GCA GAA TGC CGA ACT CGA AAG CCT GCG CTC GTT CCA TGC CTC GGT GCT GGC leu glu arg gin asn ala glu leu glu ser leu arg ser phe his ala ser val leu ala 361

CTC GGT GTC CGA CAT TCT CAT CGT CGT CTC GCG CGC GGG TCT GAT CGA GGA GGT CTC GGC ser val ser asp ile leu ile val val ser arg ala gly leu ile glu glu val ser ala 421

CTC CGT CCC GGC CCG CAC CCG CCT GCC CCG CGC GGC ACT CTG CGG GCG GCC CGC GTC GGA ser val pro ala arg thr arg leu pro arg ala ala leu cys gly arg pro ala ser asp 481

CCT CTT CGC CGA GGC CGA CCG TCC CGC GCT TCA GGA GGC GAT GCG CCG CGC CAC GGA CGC leu phe ala glu ala asp arg pro ala leu gln glu ala met arg argala thr asp ala 541

GCG CAG CGC CCT CAC CCT CGA GGC GGG GCT CGA GAC CCC CGA GGG CCC GAG CGC GGT GGA arg ser ala leu thr leu glu ala gly leu glu thr pro glu gly pro ser ala val glu 601

GCT CTC GCT GTC GCC CCG CTT CGA CGA GCG TGG CCG CGC GGC GGG CCT CGT GCT CAC CGG leu ser leu ser pro arg phe asp glu arg gly arg ala ala gly leu val leu thr gly 661

CCG GTC GGT GGC GGA GCT GCG GCA GGC CTA TGC CGA ACT GGC CGA GAG CCA TGA CGA GCT arg ser val ala glu leu arg gln ala tyr ala glu leu ala glu ser his asp glu leu 723

GAA GGC GGC GCA GGC GCT GCT GGT GCG GAA CGA GAA GCT CGC CTC GCT CGG CCG CCT CCT lys ala ala gln ala leu leu val arg asn glu lys leu ala ser leu gly arg leu leu 781

CGC GGG CGT GGC GCA TGA GCT GAA CAA TCC GAT CAG CTT CGT CTA TGC CAA TGC CCA TGC ala gly val ala his glu leu asn asn pro ile ser phe val tyr ala asn ala his ala 841

GCT CGG CCG CTA CGC CAC CAA GTT CGA GCA GTA TTT CGA GCA GGT GCA GGC GGG TGC CCC leu gly arg tyr ala thr lys phe glu gln tyr phe giu gln val gln ala gly ala pro 901

GCG CGA GGC GCT GAT CCG GCT GCG CGA GGA GCT GAA GCT CGA CCG CGA GGT GCG CAA CCT arg glu ala leu ile arg leu arg glu glu leu lys leu asp arg glu val arg asn leu 961

GCG CGA TGC GGT GCA GGG CGC GCG CGA CGG GGC CGA GCG GGT GCG CGA CAT CGT CGA GGA arg asp ala val gln gly ala arg asp gly ala glu arg val arg asp ile val glu asp 1021

CCT GCG GCG GCT CTC CTC CGA AGG ATC GGG CGA GAT GGA GGG CIT CGA CCT IGT GGC GGT leu arg arg leu ser ser glu gly ser gly glu met glu gly phe asp leu val ala val 1081

GGC GCA GGT GGC CAC CGC TTG GGT CCT GCG CGG CGC GCG CCG ACC GGT GGC GGT CGA GGT ala gin val ala thr ala trp val leu arg gly ala arg arg pro val ala val glu val 1142

CAC GGG CGA GGC CCA TCT GCC GGT GCG GGG GCG GCC CGG CCA TGT GCA GCA GGT GGT GAT thr gly glu ala his leu pro val arg gly arg pro gly his val gln gln val val met 1201

GAA CCT CGT GCA GAA CGC GCT CGA CGC GGT CGA GGA GGT GCC CGA GCC GCG CAT ITC CAT asn leu val gln asn ala leu asp ala val glu glu val pro glu pro arg ile ser ile 1261

CGA GCA CCG GAT CGA GGG CGA CCG CGC GGT GCT GAC GGT ACG CGA CAG CGG GCC GGG CGT glu his arg ile glu gly asp arg ala val leu thr val arg asp ser gly pro gly val 1321

GCC CGA GGC GCT GGC GCA GGC GAT CTI CGA TCS GTT CIT CAC CAC GAA ACC GGT GGG GCG 1381

pro glu ala leu ala gln ala ile phe asp pro phe phe thr thr lys pro val gly arg

CGG CAC CGG CCT CGG CCT GCC CAT CTC GCA CAA GAT CSC CGA AGA GCA TGG CGG GCG GCT gly thr gly leu gly leu pro ile ser his lys ile ala glu glu his gly gly arg leu 1441

CGT GCT CGG CGA GGA GGG TCC GGG CGC CGC CTT CCG CCT CGA ACT GCC GCT CGA CCG GGA val leu gly glu glu gly pro gly ala ala phe arg leu glü leu pro leu asp arg glu

Fig. 5. For legend see page 1815. 
1501

GAT CCG ATG AAC ATT CTC TGG CIT CAG GCC ICG GGC TGC GGC GGC TGC ACC ATG TCG CTC ile arg OPA

ORr2 Met asn ile leu trp leu gin ala ser gly cys gly gly cys thr met ser leu 1561

CTC TGC GCC GAG GCG CCG GGC CTC TTC GAC CTT CTC GAG GAT GCG GGC CTG TGC TTC CTG leu cys ala glu ala pro gly leu phe asp leu leu glu asp ala giy leu cys phe leu TGG CAC CCC TCG CTT TCG GTC GAG TCC GGG GCG GAG GTG CGG GCG CTC CTC GAC CGG ATC trp his pro ser leu ser val glu ser gly ala glu val arg ala leu leu asp arg ile GAG GCG GGA GCG CAG CCG CTC GAC ATC CTC TGC GTC GAG GGC GCC ATC GCG CGC GGG CCC

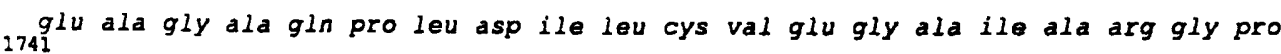
CGC GGC ACC GGA CGG ITC CAG ATG CTC GCG GGC ACC GGG CGC TCG ATG CTC GAG ACC GTC 1801 arg gly thr gly arg phe gln met leu ala gly thr gly arg ser met leu glu thr val ACG CGG CTC GCG CCC CTT GCC CGG CAT GTG GTG GCG GTG GGC AGT TGC GCG GCC TTC GGC thr arg leu ala pro leu ala arg his val val ala val gly ser cys ala ala phe gly GGG ATG ACG AGC GCG GGC GGC AAC CCC TCG GAC GCG ACG GGG CTC CAG TAC GAG GGT ACC ${ }_{1921}$ gly met thr ser ala gly gly asn pro ser asp ala thr gly leu gln tyr glu gly thr CAC GAG GGC GGC ATC CTT CCG CCC GAG TTC CGG GCG CGG GAC GGC CTG CCC GTG GTG AAT his glu gly gly ile leu pro pro glu phe arg ala arg asp gly leu pro val val ash GTC GCG GGC TGC CCG ACC CAT CCG GGC TGG GTG ACC GAG ACG CTG ATG CTG CTA GGC GGC 2041 ala gly cys pro thr his pro gly trp val thr glu thr leu met leu leu gly gly AGC GCA CTG GCG GCC GGC GAT CTC GAC CGG ITC GGC CGC CCA CGC ITC IAC GCC GAT CAT ser ala leu ala ala gly asp leu asp arg phe gly arg pro arg phe tyr ala asp his CTC GTG CAT CAC GGC TGC TCG CGC AAC GAA TAT TAC GAA TAC AAG GCC AGC GCC CGC ACC 2161 leu val his his gly cys ser arg asn glu tyr tyr glu tyr lys ala ser ala arg thr CCC GGC GAG ATC GGC TGC ATG ATG GAA CAT ATG GGC TGC ATC GGC ACG CAG GCG GTG GGC p221 gly glu ile gly cys met met glu his met gly cys ile gly thr gln ala val gly GAC IGC AAC ATC CGG CCC TGG AAC GGC AGC GGC TCC TGC ACC TCG GGC GGC TAT GCC TGC 2281 asp cys asn ile arg pro trp asn gly ser gly ser cys thr ser gly gly tyr ala cys ATC GCC IGC ACC GCG CCC GAA TTC GAG GAG CCG CGC CAC CCC TAC TCC GAG ACG CCC AAG 2341 ile ala cys thr ala pro glu phe glu glu pro arg his pro tyr ser glu thr pro lys ATC GGC GGC ATC CCG GTG GGC CTG CCC TCG GAC ATG CCG AAG GCC TGG TTC ATG GCG CTG ${ }_{2401}^{i}$ le gly gly ile pro val gly leu pro ser asp met pro lys ala trp phe met ala leu GCG AGC CTG TCC AAG GCC GCC ACG CCC GAG CGC ATA CGG CGG AAC GCG GCC TCC GAC CGG 2461 ATC GAG GTG CCC CCC ACG CTC CGG ATG CCG AAG CGA TGA CGC GGC TGG TGG TCG GCC CGT ORr3 Met thr arg leu val val gly pro phe ile glu val pro pro thr leu arg met pro lys arg OPA 2521

TCA ACC GGG TCG AGG GGG ATC ICG AGG TTC ATC IGG AGG TGG CGG AGG GCG CTG TGA CGG 2581 asn arg val glu gly asp leu glu val his leu glu val ala glu gly ala val thr ala

CGG CGC GGG TGA ATG CGC CGC TCT ACC GCG GCT TCG AGC GCA TGC TCG AGG GCC GCG ATC 2641 ala arg val asn ala pro leu tyr arg gly phe glu arg met leu glu gly arg asp pro

CCC GCG ACG CAC TGA CCA TCA CGC CGC GGA TCT GCG GGA TCT GC: arg asp ala leu thr ile thr pro arg ile cys gly ile cys

(b)

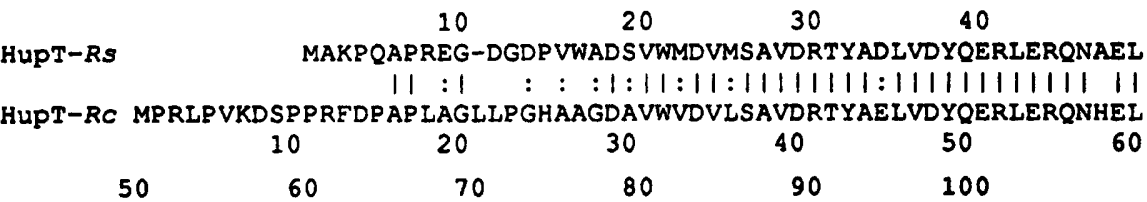

HUPT-RS ESLRSFHASVLASVSDILIVVSRAGLIEEVSASVPARTRLPRAALCGRPASDLFAEADRP $|:|||::|::|||||||||||||:::|||||||::|||::||:|1| \mid$ HUPT-RC EDLRSYLGSIFASVSDALIVVSRAGEVLGTSASVEALTGQGAGVWQGRPLAALFDPASGP $\begin{array}{llllll}70 & 80 & 90 & 100 & 110 & 120\end{array}$

Fig. 5. For legend see page 1815. 
$\begin{array}{llllll}110 & 120 & 130 & 140 & 150 & 160\end{array}$

HUPT-RS ALQEAMRRATDARSALTLEAGLETPEGP SAVELSLSPRFDERGRAAGLVLTGRSVAELRQ

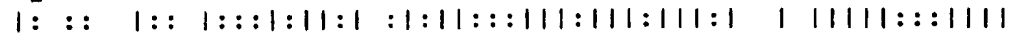

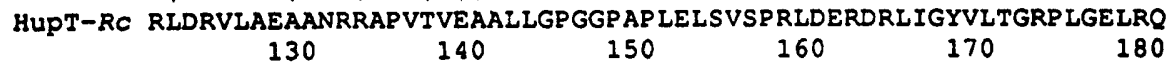

$\begin{array}{lllll}170 & 180 & 190 & 200 & 210\end{array}$

HUPT-RS AYAELAESHDELKAAQALLVRNEKLAS LGRLLAGVAHELNNP ISFVYANAHALGRYATKF

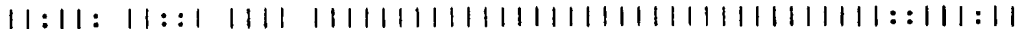
HUPT-RC AYSELERSHAALIAAQAQLVRNEKLASLGRLLAGVAHELNNP I SEVYANAHAMERYAAKF

$\begin{array}{ccccccc} & 190 & 200 & 210 & 220 & 230 & 240 \\ 230 & 240 & 250 & 260 & 270 & 280 & \end{array}$

HUPT-RS EQYFEQVQAGAPREALIRLREELKLDREVRNLRDAVQGARDGAERVRDIVEDLRRLSSEG ||$|1:|||||:||:|:||| 1||||:|||||| 1|1::||||||||||:||||||||||:|$ HUPT-RC ETYFAAVQAGATREELVALRESLKLEREVGNLRTAIDGARDGAERVRAIVEDLRRISSDG

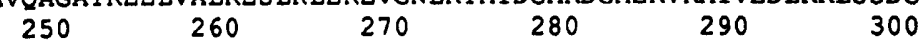

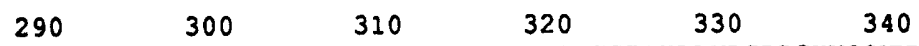

HUPT-RS SGEMEGFDLVAVAQVATAWVLRGARRPVAVEVTGEAHLPVRGRPGHVQOVVMNLVQNALD $:|| \quad|||||:|||::||||:::|||:|||||||||||:|||||||||||| \mid$ HUPT-RC TGEQVVEDLVATAGVAADWVRRGSKTAVAVDETGLAALEVIGRPGH IQQVVMNLVQNALD

$\begin{array}{rrrrrrr} & 310 & 320 & 330 & 340 & 350 & 360 \\ 350 & 360 & 370 & 380 & 390 & 400 & \end{array}$

HUPT-RS AVEEVPEPRISIEHRIEGDRAVLTVRDSGPGVPEALAQA IFDPFFTTKPVGRGTGLGLPI

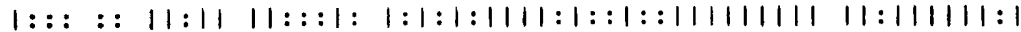
HUPT-RC AMGDFQDGRIRIEARIAAGRGELVVSDTGPGVAEDVAPTIFDPFFTTKDVGKGTGLGLSI

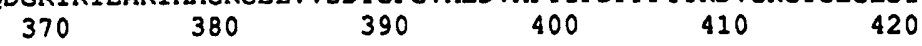
410
420
430
440

HUPT-RS SHKIAEEHGGRLVLGEEGP--GAAFRLELPLDREIR

|| $1: 1|1|||||$ | || $\mid:: 1: 1:$ :

HUPT-RC SAKIVEEHGGRLRLLPRKPAGGACFCFDLALAGDPA

(c)

$$
\begin{array}{cccc}
430 & 440 & 450 & \\
10 & 20 & 30 & 40
\end{array}
$$

$$
50
$$

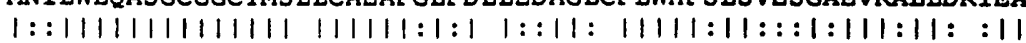
HuPU-RC MKVIWIOASGCGGCTMSAICAEAPDIIDTIATAGVEFIWHPALSLATGGEVROLIOALEA

$\begin{array}{llllll}10 & 20 & 30 & 40 & 50 & 60 \\ 70 & 80 & 90 & 100 & 110 & 120\end{array}$

HUPU1-RS GAQP LDILCVEGAIARGPRGTGRFQMLAGTGRSMLETVTRLAPLARHVVAVGSCAAFGGM

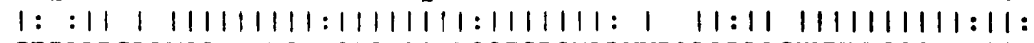
HUPU-RC GEIALDCLAVEGAIARGPMGTGRFOMLSGTGRSMLDWVRALARLAGHVVAVGSCAAYGGV

$\begin{array}{rrrrrr}70 & 80 & 90 & 100 & 110 & 120 \\ 130 & 140 & 150 & 160 & 170 & 180\end{array}$

HUPU1-RS TSAGGNP SDATGLQYEGTHEGGILPPEFRARDGLPVVNVAGCP THPGWVTETLMLLGGSA

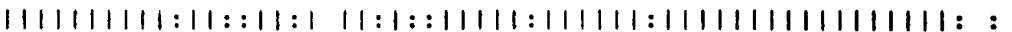
HUPU-RC TSAGGNPSDAVGLAFEGAHPGGVLAAEFRARSGLPVVNIAGCPTHPGWVTETLMLLARGH

$\begin{array}{llllll}130 & 140 & 150 & 160 & 170 & 180 \\ 190 & 200 & 210 & 220 & 230 & 240\end{array}$

HUPU1-RS LAAGDLDRFGRPREYADHLVHHGCSRNEYYEYKASARTPGE IGCMMEHMGCIGTQAVGDC

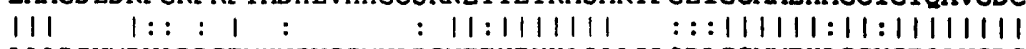
HUPU-RC LAARIWMRWADRCFMHNIWCIMVARGNEFYEYKASALQLSDLGCMMEHLGCVGTQAVGDC $\begin{array}{llllll}190 & 200 & 210 & 220 & 230 & 240\end{array}$

$\begin{array}{llllll}250 & 260 & 270 & 280 & 290 & 300\end{array}$

HUPU1-RS NIRPWNGSGSCTSGGYACIACTAPEEEEPRHPYSETPKIGGIPVGLP SDMPKAWFMALAS

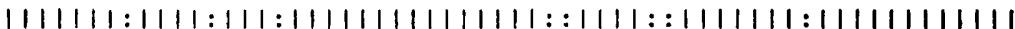
HUPU-RC NIRPWNGEGSCTRGGYPCIACTAPEFEEPRHPETETPKVAGIPVGLPADMPKAWEMALAS $\begin{array}{llllll}250 & 260 & 270 & 280 & 290 & 300\end{array}$ $310 \quad 320 \quad 330$ HUPU2-Rs $10 \quad 20$

HUPU1-RS LSKAATPERIRRNAASDRIEVPPTLRMPKR MTRLVVGPENRVEGDLEVHLEVAEG ||||||||||$:|1::|::||||:|:|: \quad|1|||||||||||||||:: 1: 1$ HUPU-RC LSKAATPERIAKNAVAPRLTVPPTIRKPRGAAMSDTPRLVVGPFNRVEGDLEVHLDLAGG $\begin{array}{llllll}310 & 320 & 330 & 340 & 350 & 360\end{array}$

$30 \quad 40 \quad 50 \quad 60$

HUPU2-RS AVTAARVNAPLYRGFERMLEGRDPRDALTITPRICGIC....

$1: 11111: 1111111111111: 1: 1111: 11111111$

HUPU-RC RVAAARVNSPLYRGEERMLEGRAPSDALTLTPRICGICSISQSAAAARALGAAMGLAPTDQ $\begin{array}{llllll}370 & 380 & 390 & 400 & 410 & 420\end{array}$ 


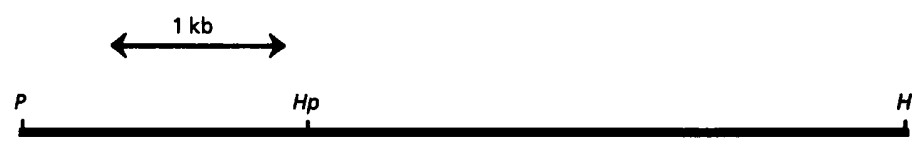

p43PH5
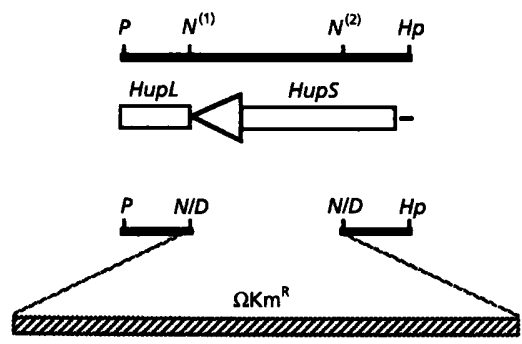

p43PHp

p43PHp:: Km
Fig. 6. Subcloning and inactivation of the $R$. sphaeroides hupSL genes. Abbreviations: Hp, Hpal; N, Ncol; P, Psti; N/D, junction between blunt-ended $\mathrm{NCOl}$ site and Dral site of the $\Omega \mathrm{Km}^{\top}$ cartridge. described, was introduced into D5 in order to obtain the D5 HupSL mutant. One of the $\mathrm{Km}^{\mathrm{r}} \mathrm{Tc}^{\mathrm{s}}$ clones, i.e. a potential double cross-over, which was expected to contain the inactivated bupSLM operon, was designated $\mathrm{D} 5 \mathrm{H}$ and analysed further.

Fig. 8(a) shows the AseI- and Dral-digestion patterns of the genomic DNA from D5 and D5H. Analysis of the AseI-digestion pattern of $\mathrm{D} 5 \mathrm{H}$ when compared to that of D5 revealed that instead of the approximately $910 \mathrm{~kb} A s e I$ band in D5, two new bands of approximately 135 and $775 \mathrm{~kb}$ appeared in $\mathrm{D} 5 \mathrm{H}$. Because the sequence of $\Omega \mathrm{Km}^{\mathrm{r}}$ cartridge contains two AseI sites separated by approximately $2 \mathrm{~kb}$, additional $A s e \mathrm{I}$ sites in the original $910 \mathrm{~kb}$ fragment of $\mathrm{D} 5 \mathrm{H}$ genomic DNA must have been due to the presence of the $\Omega \mathrm{Km}^{\mathrm{r}}$ cartridge. At the same time, no differences between the DraI-digestion patterns of the chromosomal DNA from these strains were observed. This latter observation supported the conclusion that no vector DNA (besides $\Omega \mathrm{Km}^{\mathrm{r}}$ ) from p43PHp::Km::mob, which contains two DraI sites in the sequence of pUC19, was present in the $\mathrm{D} 5 \mathrm{H}$ genomic DNA. Southern blotting (data not shown) also failed to detect pUC19 DNA in the chromosomal DNA of D5H. Thus, we concluded that D5H is a D5-based HupSL mutant. The bupSL-Rs locus is positioned approximately $208 \mathrm{~kb}$ clockwise on the map of $R$. spbaeroides 2.4 .1 chromosome I (Fig. 8b).

Mutant D5H was anticipated to be impaired in Hup activity. To confirm that $\mathrm{D} 5 \mathrm{H}$ is in fact $\mathrm{Hup}^{-}$, we examined Hup-dependent photolithotrophic growth of D5(pUI8533) and D5H(pUI8533). The presence of pUI8533 in these strains rendered them PS competent. We observed that the Hup ${ }^{-}$derivative, D5H(pUI8533), was incapable of photolithotrophic growth whereas D5(pUI8533) grew under these same conditions.
D5H was then analysed with respect to PS gene expression. No significant differences in colony pigmentation, anaerobic-dark spectra (data not shown) or puc: : lac $Z$ expression (Fig. 2) were detected between D5H and D5. Plasmid p43-KS19, harbouring bupT-Rs, was introduced into $\mathrm{D} 5 \mathrm{H}(\mathrm{pCF} 200 \mathrm{Km})$ to test for its effect on PS gene expression in the bupSL background. The presence of extra copies of bupT-Rs in D5H(pCF200Km) resulted in increased expression of the $p u c:$ : lac $Z$ fusion to approximately the same extent as when bupT-Rs was present in D5(pCF200Km) (Fig. 2). Colony pigmentation and spectra of the anaerobic-dark grown cultures of $\mathrm{D} 5 \mathrm{H}(\mathrm{p} 43-\mathrm{KS} 19)$ were virtually indistinguishable (data not shown) from those of the corresponding D5(p43KS19). Likewise, the presence of pUI8533 (containing $\operatorname{prr} A$ and $\operatorname{prr} B)$ in $\mathrm{D} 5 \mathrm{H}(\mathrm{pCF} 200 \mathrm{Km})$ resulted in $\beta$-Gal levels similar to those observed in $\mathrm{D} 5(\mathrm{pCF} 200 \mathrm{Km}$, pUI8533) (Fig. 2).

Since under the conditions tested, both D5 and D5H behaved almost identically with respect to PS gene expression, a functional Hup system appears not to be required for the effect of HupT-Rs on PS gene expression in R. sphaeroides 2.4.1.

\section{The site of HupT-Rs control on PS gene expression}

Because HupT-Rs affected expression of PS genes in the mutant D5, which is impaired in the histidine-kinase $\operatorname{PrrB}$, and because PrrA is a response regulator acting downstream of PrrB in the same transduction pathway, we sought to investigate whether or not the PrrA protein was required for HupT-Rs to exert its effect on PS gene expression. If the effect of HupT-Rs is dependent on $\operatorname{PrrA}$, then we would anticipate that in the absence of $\operatorname{Prr}$, the effect of HupT-Rs should disappear. To test this hypothesis, p43-KS19 was introduced into a previously

Fig. 5. (a) Nucleotide and deduced amino acid sequences of the $1.9 \mathrm{~kb}$ Kpnl-Sad fragment as well as the sequence downstream from the Kpnl site (accession number L37195). Proposed ribosome-binding sites are underlined. (b) Alignment of the sequences of HupT proteins from R. sphaeroides 2.4.1 (HupT-Rs) and $R$. capsulatus (HupT-RC) (Elsen et al., 1993) using the FASTA program from the GCG software package. Vertical lines connect identical residues, colons connect homologous residues. (c) Amino acid sequence alignment of HupU1-Rs, HupU2-Rs ( $N$ terminus) proteins and HupU-Rc (Elsen et al., 1993). 
(a)
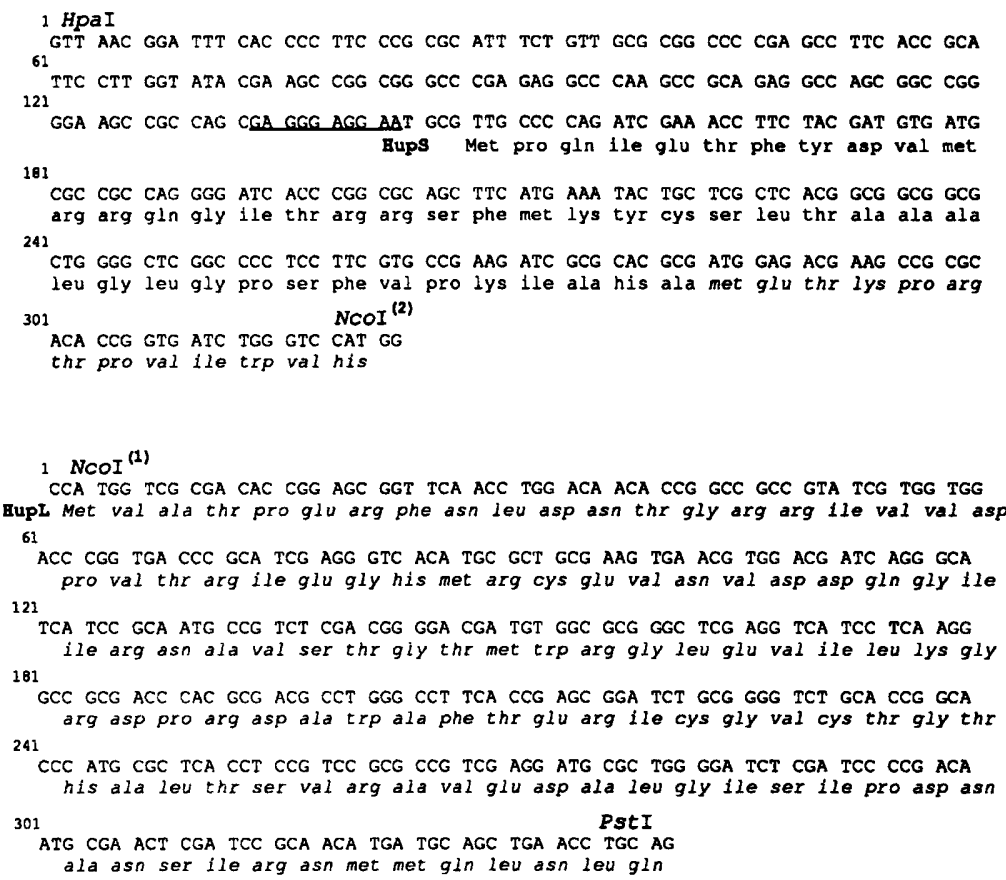

(b)

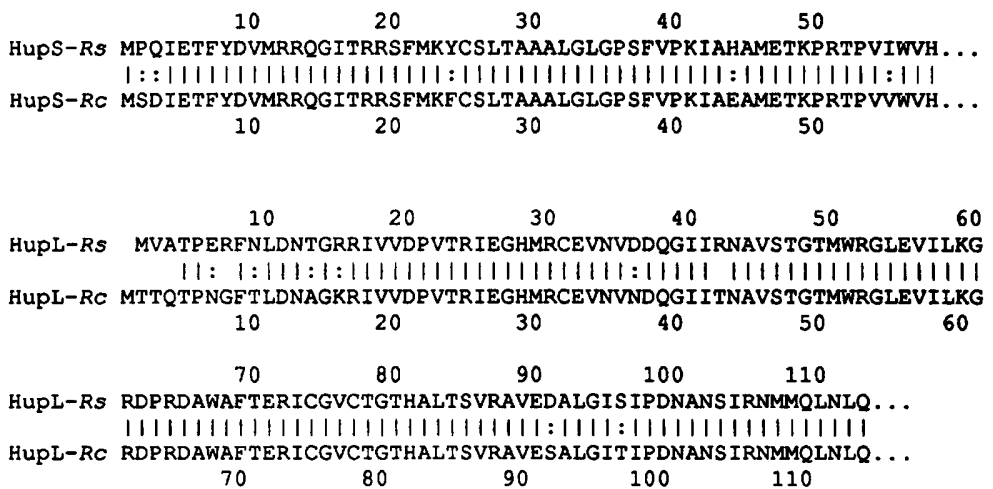

Fig. 7. (a) Nucleotide and deduced amino acid sequences of the Hpal-Ncol (2) and Ncol ${ }^{(1)}$ - Pstl fragments (accession numbers L37196 and L37194 respectively) shown in Fig. 6. The proposed ribosome-binding site for hups is underlined. The presumed leader sequence of HupS is shown in a plain font; sequences of the mature proteins are italicized. (b) Amino acid sequence alignment of $\mathrm{N}$-termini of HupS and HupL proteins from $R$. sphaeroides 2.4.1, HupS-Rs and HupL-Rs, and their homologues from $R$. capsulatus, correspondingly HupS-RC and HupL-Rc (Leclerc et al., 1988). constructed PrrA mutant, PRRA1 (Eraso \& Kaplan, 1994). No differences in colony pigmentation, in photosynthetic spectral complexes (Fig. 3, traces A and B) or in puc::lacZ expression in PRRA1(pCF200Km) were observed when p43-KS19, containing bupT-Rs, or pRK4150 (vector) was provided in trans (Fig. 2). Therefore an intact $\operatorname{prr} A$ gene product was required for HupT$R s$ to exert its effect on PS gene expression.

\section{DISCUSSION}

In the purple photosynthetic bacteria colony pigmentation has been traditionally used as an indicator of PS gene expression. Several trans-acting factors have been isolated by the use of this approach (Eraso \& Kaplan, 1994; Pollich et al., 1993; Sganga \& Bauer, 1992). Although proven successful, this approach has some obvious limitations, e.g. accumulation of the coloured pigments may not coincide with expression of the PS genes of interest; changes in pigmentation may result from mutations not related to gene regulation.

We therefore developed an approach, using a puc:: lac $Z$ transcriptional fusion, which on the one hand allowed us to directly monitor transcription of the chosen PS gene under various defined growth conditions and at the same time was amenable to complementation analysis. Using this approach we isolated a number of potential regulatory mutants which fell into three broad classes. The regulatory mutants of classes I and II were the most impaired in PS gene expression and specifically, in the oxygen dependent regulation of PS gene expression. In this study we analysed only mutants of class I, using mutant D5 as a representative.

Complementation analysis and eventual DNA sequencing of the mutation in D5 revealed that the mutation is 

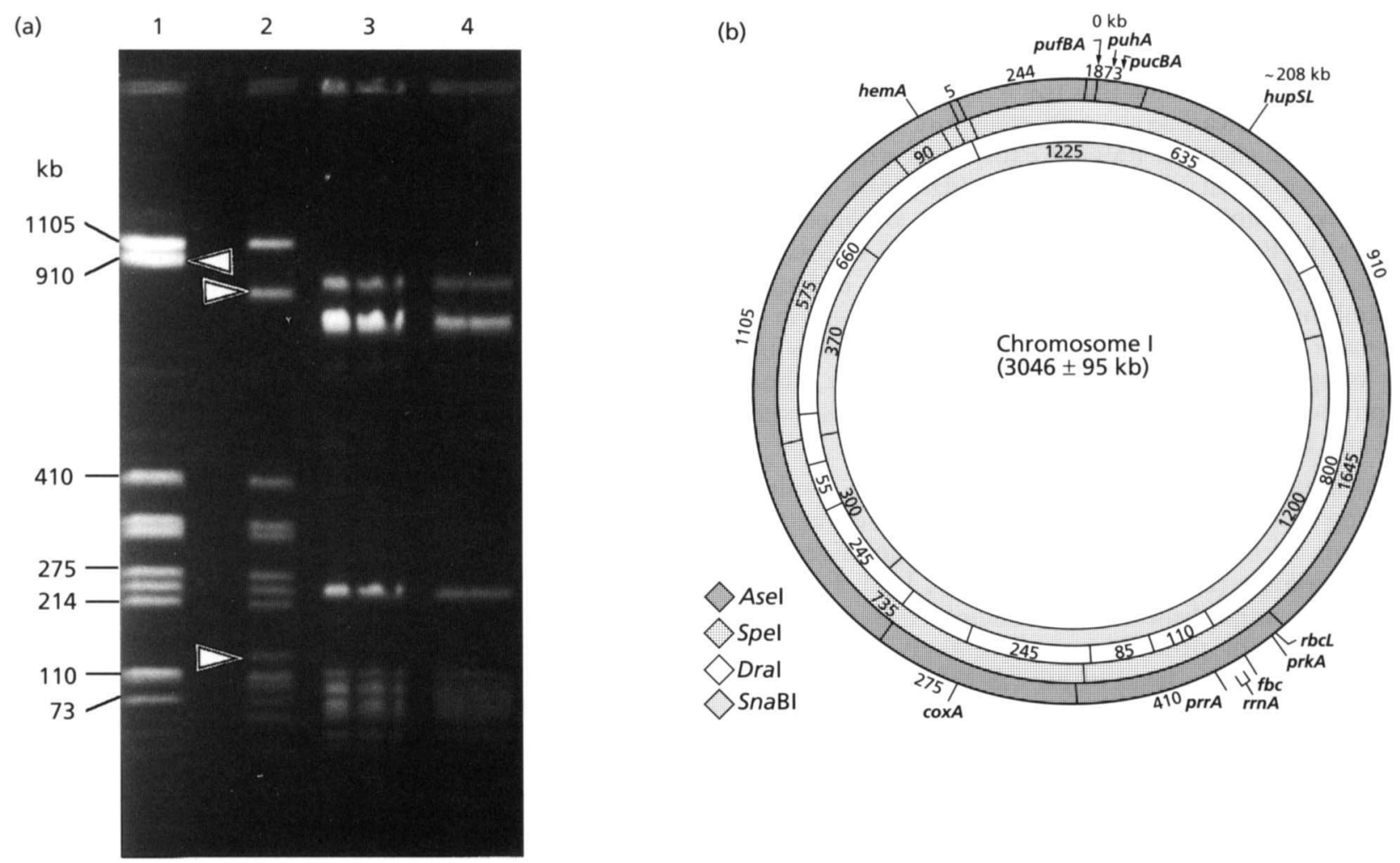

Fig. 8. (a) Pattern of pulsed-field gel electrophoresis of the genomic DNA from the strains D5 (traces 1 and 3 ) and D5H (traces 2 and 4) digested with Asel (traces 1 and 2) or Dral (traces 3 and 4). Arrows indicate the bands which differ in the patterns of D5 and D5H. Sizes of the Asel fragments of $R$. sphaeroides 2.4 .1 are as described in Suwanto \& Kaplan (1989). (b) Localization of the hup genes on chromosome I of $R$. sphaeroides.

present in the $\operatorname{prr} B$ gene, encoding the sensor kinase, which together with the $\operatorname{prrC}$ (Eraso \& Kaplan, 1995) and $\operatorname{prr} A$ (Eraso \& Kaplan, 1994) gene products constitutes a regulatory system involved in oxygen-related regulation of PS gene expression in R. sphaeroides. The further analysis of class I mutants as well as mutants from other mutant classes has resulted in the finding of additional regulatory loci involved in PS gene expression (Gomelsky \& Kaplan, 1994b). When taken together, this approach to the identification of regulatory mutations affecting PS gene expression has proven to be successful.

There still remained several unanswered questions, namely: why in the apparent absence of a functional PrrB is the aerobic expression of puc: : lac $Z$ in mutant D5 higher than in the WT, why in the apparent absence of a functional $\operatorname{Pr} B$ do extra copies of prr $A$ rescue the mutant phenotype, and what is the basis for the partial complementation observed in response to the presence of several cosmids containing neither $\operatorname{prr} B$ nor $\operatorname{prr} A$ ?

To address the last question, we analysed one of the cosmids, pUI8043, responsible for partial complementation of class I mutants. Our analysis revealed that a single gene, which appeared to be a homologue of bupT from $R$. capsulatus (Elsen et al., 1993) was responsible for the partial complementation. We have also shown that the effect of HupT on PS gene expression was mediated through PrrA but independent of a functional Hup hydrogenase, the putative primary target for regulation by HupT. The similarity in the primary structure of Hup'T to other members of the family of histidine-kinases (Stock et al., 1989) and the proposed function of HupT as a sensor kinase for bup gene expression in R. capsulatus (Elsen et al., 1993) lead to the conclusion that the partial complementation of class I mutants was due to the kinase activity of HupT. Thus, HupT provided in extra copies can partially substitute for PrrB in phosphorylating PrrA, which results in the activation of PS gene expression. This phenomenon of phosphorylation of a response regulator by a heterologous histidine-kinase, designated cross-talk, has been well documented in E. coli and other bacteria (Wanner, 1992, and references therein). However, to our knowledge this is the first demonstration of cross-talk in the anaerobic photosynthetic bacteria.

pUI8043 was one of nine cosmids (of a total of approximately 800 ), which both showed partial complementation of class I mutants and also failed to exert their effect on PS gene expression in a $\operatorname{PrrA}^{-}$background (data not shown). Therefore it is reasonable to assume that some or all of these eight additional cosmids contain genes for yet other cellular histidine-kinases. However, these cosmids have not yet been characterized at the DNA level. The total number of two-component regulatory systems in E. coli, for example, is estimated to be approximately 50 (Hazelbauer et al., 1993). If a similar number were to apply 
to R. sphaeroides, then most of the histidine-kinases present in extra copies failed to influence PS gene expression. In this regard we confirmed that the R. sphaeroides histidinekinase for the dicarboxylic acid transport system, DctS, has negligible effect on PS gene expression when present in extra copies in class I mutants (data not shown). Therefore, HupT bears some measure of specificity towards the PrrA regulator. It is not difficult to imagine that such physiologically related processes as hydrogen metabolism and photosynthetic energy entrapment in $R$. sphaeroides might be cross-regulated. However it is too early to speculate, with the limited data available, about the physiological significance of the cross-talk between PrrB and HupT.

The location of the mutation in D5 is shown to result in a reading frame-shift in the $5^{\prime}$ coding sequence of the $\operatorname{prr} B$ gene prior to the crucial histidine involved in phosphorylation (Eraso \& Kaplan, 1995; J. M. Eraso \& S. Kaplan, unpublished data). Hence, this particular mutant does not produce an active PrrB kinase. Our observation that the level of puc: : lac $Z$ expression in the PrrB mutant D5(pCF200Km, pLA2917) was higher than in the WT, 2.4.1(pCF200Km, pLA2917), under aerobic conditions (Fig. 2), might indicate that under these conditions WT PrrB, besides having kinase activity, is also able to suppress phosphorylation of PrrA by heterologous kinases. Therefore $\operatorname{Prr} B$ may also possess a phosphatase activity toward $\operatorname{Prr} A$ as has been shown for a number of histidine-kinases (Parkinson, 1993, and references therein). In accord with this prediction is the fact that under aerobic conditions, the expression of puc:: lac $Z$ is much more sensitive to extra copies of bupT in the PrrB mutant D5 than in the WT strain: under aerobic conditions, there is an approximately 5 -fold difference in the levels of $\beta$-Gal between D5 $(\mathrm{pCF} 200 \mathrm{Km}$, $\mathrm{p} 43-\mathrm{KS} 19)$ and D5(pCF200Km, pLA2917); however only an approximately $1 \cdot 7$-fold difference between 2.4.1(pCF200Km, p43-KS19) and 2.4.1(pCF200Km, pLA2917) (Fig. 2). Our assumption of a phosphatase activity toward PrrA attributable to PrrB, based on the analysis of cross-talk, correlates well with the conclusions made by Eraso \& Kaplan (1995), based on the PS gene expression in the PrrB and PrrA mutants. The study of the $\operatorname{Reg} B$ and $\operatorname{RegA}$ mutants of $R$. capsulatus also suggests that $\operatorname{Reg} B$, an R. capsulatus counterpart of PrrB, may also posess a phosphatase activity (Mosley et al., 1994).

Evidence that PrrA may be subject to phosphorylation by heterologous histidine-kinases, like bupT, explains why extra copies of $\operatorname{prr} A$ are capable of complementing the prrB mutation in D5. It also sheds light on the observation that, in the WT strain, extra copies of $\operatorname{prr} A$ activate the expression of PS genes to the extent that photosynthetic complexes are formed even under aerobic conditions (Eraso \& Kaplan, 1994). It seems therefore plausible that the amount of the phosphorylated form of PrrA is limiting to PS gene expression.

In conclusion, we have described the use of a $p u c:$ : lac $Z$ transcriptional fusion as a reporter for the identification, isolation and complementation of regulatory mutants in PS gene expression. Because of the sensitivity of this method, we were able to identify cosmids which were able either fully or partially to restore PS gene expression in class I mutants. In the case of the former, we discovered that the mutation in mutant D5 resides in the prrB gene. Partial complementation, on the other hand, was shown to be due to the heterologous kinase, HupT. These observations raise the question and possible direction of future studies of the physiological significance of the cross-talk between PS gene expression and physiologically related processes, e.g. hydrogen metabolism, in $R$. sphaeroides. If nothing else, those cosmids which, like pUI8043, partially complement the mutation in $\operatorname{prr} B$ but not in $\operatorname{prr} A$, may be useful in the identification of other histidine kinases comprising two-component regulatory systems in R. sphaeroides. On the other hand, those cosmids which partially complement both the $\operatorname{prr} B$ and $\operatorname{prr} A$ mutations may provide a source for identification of additional transcriptional factors controlling PS gene expression in R. sphaeroides (Gomelsky \& Kaplan, 1994b). In the course of this study we cloned and characterized some of the bup genes from R. sphaeroides and found that their structure and organization are similar to those in $R$. capsulatus.

\section{ACKNOWLEDGEMENTS}

We thank J. K. Lee and J. M. Eraso for the strains and plasmids provided, J. M. Eraso for sequencing the mutation in D5, K. Nereng for assistance with pulsed-field gel electrophoresis, and D. Needleman and Y. Wang for performing automated DNA sequencing. M.G. is also grateful to J.K. Lee for useful discussions.

This work was supported by NIH grants GM15590 and GM31667 to S.K.

\section{REFERENCES}

Allen, L. N. \& Hanson, R. S. (1985). Construction of broad-hostrange cosmid cloning vectors: identification of genes necessary for growth of Methylobacterium organophilum on methanol. $J$ Bacteriol 161, 955-962.

Bauer, C. E., Bollivar, D. W. \& Suzuki, J. Y. (1993). Genetic analysis of photopigment biosynthesis in eubacteria: a guiding light for algae and plants. $J$ Bacteriol 175, 3919-3925.

Cohen-Bazire, G., Sistrom, W. R. \& Stanier, R. Y. (1957). Kinetic studies of pigment synthesis by non-sulfur purple bacteria. $J$ Cell Comp Physiol 49, 25-68.

Colbeau, A., Kelley, B. C. \& Vignais, P. M. (1980). Hydrogenase activity in Rbodopseudomonas capsulata: relationship with nitrogenase activity. J Bacteriol 144, 141-148.

Colbeau, A., Richaud, P., Toussaint, B., Caballero, F. J., Elster, C., Delphin, C., Smith, R. L., Chabert, J. \& Vignais, P. M. (1993). Organization of the genes necessary for hydrogenase expression in Rbodobacter capsulatus. Sequence analysis and identification of two byp regulatory mutants. Mol Microbiol 8, 15-29.

Davis, J., Donohue, T. J. \& Kaplan, S. (1988). Construction, characterization, and complementation of a Puf ${ }^{-}$mutant of Rhodobacter sphaeroides. J Bacteriol 170, 320-329.

Dryden, S. C., \& Kaplan, S. (1990). Localization and structural analysis of the ribosomal RNA operons of Rhodobacter sphaeroides. Nucleic Acids Res 18, 7267-7277.

Elsen, S., Richaud, P. Colbeau, A. \& Vignais, P. M. (1993). Sequence analysis and interposon mutagenesis of the bup $T$ gene, which 
encodes a sensor protein involved in repression of hydrogenase synthesis in Rhodobacter capsulatus. J Bacteriol 175, 7404-7412.

Eraso, J. M. \& Kaplan, S. (1994). $\operatorname{prr} A$, a putative response regulator involved in oxygen regulation of photosynthesis gene expression in Rhodobacter sphaeroides. J Bacteriol 176, 32-43.

Eraso, J. M. \& Kaplan, S. (1995). Oxygen-insensitive synthesis of the photosynthetic membranes of Rhodobacter sphaeroides: a mutant histidine kinase. J Bacteriol 177, 2695-2706.

Gibson, L. C. D., McGlynn, P., Chaudri, M. \& Hunter, C. N. (1992). A putative anaerobic coproporphyrinogen III oxidase in Rhodobacter sphaeroides. II. Analysis of a region of the genome encoding bem $F$ and the puc operon. Mol Microbiol 6, 3171-3186.

Gomelsky, M. \& Kaplan, S. (1994a). A proposed histidine-kinase for hydrogen uptake (HupR2) of Rhodobacter sphaeroides can activate $\operatorname{Prr} A$, the response regulator of photosynthesis gene expression. In Abstracts, VIII International Symposium on Phototrophic Procaryotes, abstract 139B. Sant'Angelo in Vado, Italy: Tipolitografia Grafica Vadese.

Gomelsky, M. \& Kaplan, S. (1994b). Identification of transcription factors involved in the regulation of photosynthesis gene expression in Rhodobacter sphaeroides 2.4.1. In Abstracts, VIII International Symposium on Phototropbic Procaryotes, abstract 41B. Sant'Angelo in Vado, Italy: Tipolitografia Grafica Vadese.

Hazelbauer, G. L., Berg, H. C. \& Matsumura, P. (1993). Bacterial motility and signal transduction. Cell 73, 15-22.

Inoue, K., Kouadio, J-L. K., Mosley, C. S. \& Bauer, C. E. (1995). Isolation and in vitro phosphorylation of sensory transduction components controlling anaerobic induction of light harvesting and reaction center gene expression in Rhodobacter capsulatus. Biochemistry 34, 391-396.

Keen, N. T., Tamaki, S., Kobayashi, D. \& Trollinger, D. (1988). Improved broad-host-range plasmids for DNA cloning in Gramnegative bacteria. Gene 70, 191-197.

Kiley, P. J. \& Kaplan, S. (1987). Cloning, DNA sequence, and expression of the Rhodobacter sphaeroides light-harvesting B800-850$\alpha$ and B800-850- $\beta$ genes. $J$ Bacteriol 169, 3268-3275.

Kiley, P. J. \& Kaplan, S. (1988). Molecular genetics of photosynthetic membrane biosynthesis in Rhodobacter sphaeroides. Microbiol Rev 52, 50-69.

Lang, H. P., Cogdell, R. J., Gardiner, A. T. \& Hunter, C. N. (1994). Early steps in carotenoid biosynthesis: sequences and transcriptional analysis of the $c r t I$ and $c r t B$ genes of Rhodobacter sphaeroides and overexpression and reactivation of $\mathrm{crtI}$ in Eschericbia coli and $R$. sphaeroides. J Bacteriol 176, 3859-3869.

Leclerc, M., Colbeau, A., Cauvin, B. \& Vignais, P. M. (1988). Cloning and sequencing of the large and the small subunits of the $\mathrm{H}_{2}$ uptake hydrogenase (bup) of Rhodobacter capsulatus. Mol \& Gen Genet 214, 97-107. Erratum 215, 368.

Lee, J. K. \& Kaplan, S. (1992a). cis-acting regulatory elements involved in oxygen and light control of puc operon transcription in Rbodobacter sphaeroides. J Bacteriol 174, 1146-1157.

Lee, J. K. \& Kaplan, S. (1992b). Isolation and characterization of trans-acting mutations involved in oxygen regulation of puc operon transcription in Rhodobacter sphaeroides. J Bacteriol 174, 1158-1171.
Lee, J. K., DeHoff, B. S., Donohue, T. J., Gumport, R. I. \& Kaplan, S. (1989a). Transcriptional analysis of puf operon expression in Rbodobacter sphaeroides 2.4 .1 and an intercistronic transcription terminator mutant. J Biol Chem 264, 19354-19365.

Lee, J. K., Kiley, P. J. \& Kaplan, S. (1989b). Posttranscriptional control of puc operon expression of B800-850 light-harvesting complex formation in Rhodobacter sphaeroides. J Bacteriol 171, 3391-3405.

Madigan, M., Cox, J. C. \& Gest, H. (1982). Photopigments in Rbodopseudomonas capsulata cells grown anaerobically in darkness. $J$ Bacteriol 150, 1422-1429.

Maniatis, T., Fritsch, E. F. \& Sambrook, J. (1982). Molecular Cloning: a Laboratory Manual. Cold Spring Harbor, NY: Cold Spring Harbor Laboratory.

McGlynn, P. \& Hunter, C. N. (1993). Genetic analysis of the $b c b C$ and $b c h A$ genes of Rhodobacter sphaeroides. Mol \& Gen Genet 236, 227-234.

Mosley, C. S., Suzuki, J. Y. \& Bauer, C. E. (1994). Identification and molecular characterization of a sensor kinase responsible for coordinating light harvesting and reaction center gene expression in response to anaerobiosis. J Bacteriol 176, 7566-7573.

Parkinson, J. S. (1993). Signal transduction schemes of bacteria. Cell 73, 857-871.

Phillips-Jones, M. K. \& Hunter, C. N. (1994). Cloning and nucleotide sequence of $\operatorname{reg} A$, a putative response regulator gene of Rhodobacter sphaeroides. FEMS Microbiol Lett 116, 269-276.

Pollich, M., Jock, S. \& Klug, G. (1993). Identification of a gene required for the oxygen-regulated formation of the photosynthetic apparatus of Rbodobacter capsulatus. Mol Microbiol 10, 749-757.

Sganga, M. W. \& Bauer, C. E. (1992). Regulatory factors controlling photosynthetic reaction center and light-harvesting gene expression in Rhodobacter capsulatus. Cell 68, 945-954.

Simon, R., Priefer, U. \& Puhler, A. (1983). A broad host range mobilization system for in vivo genetic engineering: transposon mutagenesis in Gram negative bacteria. Bio/Technology 1, 37-45.

Stock, J. B., Ninfa, A. J. \& Stock, A. M. (1989). Protein phosphorylation and regulation of adaptive responses in bacteria. Microbiol Rev 53, 450-490.

Suwanto, A. \& Kaplan, S. (1989). Physical and genetic mapping of the Rhodobacter spbaeroides 2.4 .1 genome: genome size, fragment identification and gene localization. J Bacteriol 171, 5840-5849.

Vignais, P. M. \& Toussaint, B. (1994). Molecular biology of membrane-bound $\mathrm{H}_{2}$ uptake hydrogenases. Arch Microbiol 161, $1-10$.

Wanner, B. L. (1992). Is cross regulation of two-component response regulator proteins important in bacteria? J Bacteriol 174, 2053-2058.

Yanisch-Perron, C., Viera, J. \& Messing, J. (1985). Improved M13 phage cloning vectors and host strains: nucleotide sequences of the M13mp18 and pUC19 vectors. Gene 33, 103-119.

Received 10 April 1995; accepted 19 April 1995. 